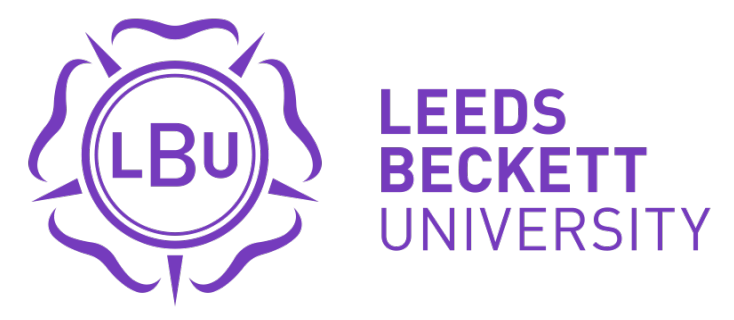

Citation:

Geeson-Brown, T and Jones, B and Till, K and Chantler, S and Deighton, K (2020) Body composition differences by age and playing standard in male rugby union and rugby league : A systematic review and meta-analysis. Journal of Sports Sciences. ISSN 0264-0414 DOI: https://doi.org/10.1080/02640414.2020.1775990

Link to Leeds Beckett Repository record:

https://eprints.leedsbeckett.ac.uk/id/eprint/6702/

Document Version:

Article (Accepted Version)

This is an Accepted Manuscript of an article published by Taylor \& Francis in Journal of Sports Sciences on 16 June 2020, available online: http://www.tandfonline.com/10.1080/02640414.2020.1775990

The aim of the Leeds Beckett Repository is to provide open access to our research, as required by funder policies and permitted by publishers and copyright law.

The Leeds Beckett repository holds a wide range of publications, each of which has been checked for copyright and the relevant embargo period has been applied by the Research Services team.

We operate on a standard take-down policy. If you are the author or publisher of an output and you would like it removed from the repository, please contact us and we will investigate on a case-by-case basis.

Each thesis in the repository has been cleared where necessary by the author for third party copyright. If you would like a thesis to be removed from the repository or believe there is an issue with copyright, please contact us on openaccess@leedsbeckett.ac.uk and we will investigate on a case-by-case basis. 
Body composition differences by age and playing standard in male rugby union and rugby league: A systematic review and meta-analysis

Tom Geeson-Brown ${ }^{1,2}$, Ben Jones ${ }^{1,2,4,5,6}$, Kevin Till ${ }^{1,2}$, Sarah Chantler ${ }^{1,3}$, Kevin Deighton ${ }^{1}$

${ }^{1}$ Leeds Beckett University, Carnegie Applied Rugby Research (CARR) centre, Institute for Sport, Physical Activity and Leisure, Leeds, United Kingdom

${ }^{2}$ Leeds Rhinos Rugby League club, Leeds, United Kingdom

${ }^{3}$ Yorkshire Carnegie Rugby Union club, Leeds, United Kingdom

${ }^{4}$ England Performance Unit, The Rugby Football League, Leeds, United Kingdom

${ }^{5}$ School of Science and Technology, University of New England, Armidale, NSW, Australia.

${ }^{6}$ Division of Exercise Science and Sports Medicine, Department of Human Biology, Faculty of Health Sciences, the University of Cape Town and the Sports Science Institute of South Africa, Cape Town, South Africa

Address for correspondence

Tom Geeson-Brown,

Carnegie Applied Rugby Research (CARR) centre, Institute for Sport, Physical Activity and Leisure,

Headingley Campus, Leeds Beckett University, West Yorkshire, LS6 3QS

Email: t.w.geeson-brown@leedsbeckett.ac.uk 
Body composition differences by age and playing standard in male rugby union and rugby league: A systematic review and meta-analysis

\author{
Abstract \\ Objective \\ This systematic review and meta-analysis aimed to determine differences in body composition between playing \\ standard and age in male rugby union and rugby league athletes. \\ Eligibility criteria
}

The MOOSE (Meta-analysis of Observational Studies in Epidemiology) guidelines for design, implementation, and reporting were followed. Studies were required to be in male rugby union or league and have body composition as the primary or secondary outcome. Data was required to be presented separately for positional groups and body composition presented as whole-body.

Data sources

PubMed, Cochrane Library, MEDLINE, SPORTDiscus, and CINHAHL via EBSCOhost. Risk of bias

The methodological quality of the included studies was evaluated using a modified assessment scale Results

58 studies were included for meta-analysis. Results highlighted significantly higher fat-free mass in senior elite than senior sub-elite or junior elite athletes for all RU and RL forwards. Small and non-significant differences were found in fat mass between rugby union playing standards and age categories. Rugby league senior elite forwards had less fat mass than junior elite forwards.

Conclusions

Practitioners should prioritise training and nutritional strategies that maximise fat-free mass development, especially in junior elite cohorts.

Key Words: Body composition; Muscle; Team Sports; Nutrition; Fat-free mass 


\section{Body composition differences by age and playing standard in male rugby union and rugby league: A systematic review and meta-analysis}

\section{Introduction}

Rugby league (RL) and rugby union (RU) are intermittent, contact-skill-based evasion team sports [1,2]. Rugby league has fewer on-field players (13 vs 15) and only permitted 6 tackles before the ball is handed to the opposition, whereas in RU, the phases of play are unlimited. Despite distinct differences in tactical and technical match play, they're both played over 80 minutes at senior level and contain the same fundamental movements (i.e. tackling, passing, and kicking). Subsequently, both RL and RU match play and training requires players to perform frequent bouts of high intensity activity (e.g., sprinting, side stepping, collisions \& jumping) alongside periods of lower intensity work (e.g., standing, walking or jogging) [3-5].

Such high intensity activities involve well developed physical qualities which are closely associated with players' body composition. Players require well developed muscular strength, speed and power [6, 7], which can be improved by increasing fat free mass (FFM, often used as a proxy measure of lean mass) $[8,9]$. Alternatively, high amounts of fat mass (FM) can negatively affect power to weight ratio and reduce acceleration ability [10], which may impair performance. Due to their strenuous training, rugby players are thought to have greater bone mineral density (BMD) than the general population [11], which is likely advantageous in preventing skeletal injuries.

Rugby players are typically classified into two positional groups; forwards and backs $[12,13]$. For both RL and RU, backs typically undertake more running than forwards, and forwards are exposed to more collisions than backs during a match $[14,15,5]$. The difference in match demands is likely indicative of the specific body composition profiles of players. For example, both RL and RU forwards have greater FFM and FM than backs $[16,17]$, likely due to a higher frequency of collisions and lower running demands [14].

Previous research investigating the body composition of rugby players is often limited by small sample sizes or the inclusion of only a single club for data analysis. Findings suggest that differences in body composition may exist between senior and junior players [18], and between elite and sub-elite players [19, 20]. However, the consistency and magnitude of these observations has not been evaluated. Understanding these differences can provide insights into the physical characteristics of rugby players and may guide the development of specific 
body composition goals, as players aim to transition between junior and senior elite squads, and between subelite and elite standards. It is important for applied practitioners to be able to adopt an evidence-based approach when working with athletes to be confident in optimising the body composition of players.

This systematic review and meta-analysis provides the first quantitative synthesis of body composition outcomes in rugby research and evaluates the differences between age (junior vs. senior) and playing standard (elite vs. sub-elite). These findings can help guide practitioners who have a focus on supporting the physical development of rugby players.

\section{Methods}

This systematic review and meta-analysis was conducted in accordance with the recommendations outlined in the 'Meta-analysis of observational studies in epidemiology' [21].

\subsection{Literature Search}

A systematic search of the following databases: PubMed and the Cochrane Library as well as MEDLINE, SPORTDiscus, and CINHAHL via EBSCOhost took place. All published studies up to October 2019 were included. No publication year or language restrictions were applied during the searches. Reference lists of eligible studies and review articles were also searched. The combinations of key words and specific search parameters can be found in Supplementary document 1. If only the abstract or partial data were published, then the author was contacted for the full data set.

\subsection{Inclusion and exclusion criteria}

For inclusion, studies were required to be human studies that measured the body composition of rugby players as the primary or secondary outcome of the study (i.e., clearly outlined assessment protocol and not solely as the descriptive characteristics of study participants). Body composition data were required to be presented separately for positional groups to be included (i.e., forwards and backs). Studies were included if they were published in peer-review journals or were available as published conference proceedings, theses or dissertations, to minimise the effect of any potential publication bias. Baseline data from intervention studies were included, as well as data from cross-sectional research. Studies were excluded if: (i) only segmental, not whole-body 
composition was measured, (ii) participants were competing in parasports, (iii) female, (iv) not rugby union or league (e.g. rugby sevens), (v) data was not split into positional groups (i.e. presented as 'all').

Two researchers independently screened the titles and abstracts of studies to assess eligibility for inclusion. Any disagreements over inclusion or exclusion were settled by a third reviewer. Potential studies that were not excluded based on their title or abstract were retrieved in full-text and reviewed against the inclusion/exclusion criteria independently by two researchers. Any disagreements over inclusion or exclusion were settled by a third reviewer. In total, 58 studies met the inclusion criteria and were included in this meta-analysis (supplementary document 3). For a body composition variable (fat free mass [FFM], fat mass [FM], percentage fat mass [\%FM], bone mineral content $[\mathrm{BMC}]$, or skinfold anthropometry [SF]) to be included in the meta-analysis a minimum of three studies across all subgroups, measuring the respective variable, were required to meet the inclusion criteria. The individual study characteristics and outcome variables for all studies which met the inclusion criteria (including those that did not have sufficient comparisons to be meta-analysed) are presented in Supplementary document 2 .

\subsection{Data abstraction}

Data were extracted by one researcher into a standardised spreadsheet and then cross checked by another reviewer. Any disagreements were settled by a third author. Data for the following variables were extracted: study information, population (sample size, rugby code, age, sex, standard, and position), body composition assessment method (skinfold anthropometry [SF], Dual-energy X-ray absorptiometry [DXA], Bioelectrical impedance (BIA)), and body composition data for each body composition variable (FFM, FM, \%FM, BMC, SF) assessed. Plot digitizer was used to obtain data when the outcome measure was only present in graphic form.

\subsection{Sub-group classification}

Participants in an under-19-year-old (U19) squad and below were classified as junior, while all others were senior. Participants in a top tier international squad or who were professionally contracted as a senior or academy player were classified as elite, while all others were classified as sub-elite [22].

2.5 Assessment of Risk of Bias in included studies 
The methodological quality of the included studies was evaluated using a modified assessment scale [23] by two authors. A third reviewer was consulted when disagreements occurred. The scale was modified to assess 10 (numbers 1-4, 6, 7, 11, 12, 16, 20) of the initial 27 criteria. This was due to the irrelevance of some questions as no intervention data was used from the included studies in this review. Question 20 was adjusted to assess if papers clearly outlined and referenced their body composition assessment methodology. The average score of included studies was 8 out of 10 . No studies were eliminated on the basis of methodological quality.

\subsection{Statistical analysis}

If outcome values were reported as median and range then they were converted to mean and standard deviation (SD) [24]. If reported as confidence intervals (CIs) or standard error of the mean (SEM) then they were converted to mean and SD [25]. Data were analysed separately for rugby codes and positional groups (i.e., forwards and backs) due to the differences in match demands and physical characteristics between these groups. Statistical comparisons (using subgroup analyses) were made between age groups (senior and junior) and playing standards (elite and sub-elite).

If studies provided body composition data on individual playing positions (e.g., scrum-half) then means and standard deviations were pooled into positional groups (i.e., forwards and backs) [26]. All analyses were conducted using Comprehensive Meta-analysis Software (version 3, Biostat, Englewood, NJ, USA). A random effects model was employed for all analyses based on the assumption that heterogeneity would exist between included studies due to the variability between teams [27]. Heterogeneity between studies was assessed using the $\mathrm{I}^{2}$ statistic, Cochrane's Q statistic and Tau-squared statistic. The magnitude of heterogeneity was classified using the $\mathrm{I}^{2}$ value, where $>75 \%$ indicates high heterogeneity, $25-75 \%$ indicates moderate heterogeneity, $<25 \%$ indicates low heterogeneity [28]. To assess whether any between group effects were dependant on a single study, sensitivity analysis was used for each variable by repeating the analysis with each study omitted in turn.

\section{Results}

Overview

Supplementary document 3 outlines the flow chart of study selection. Of the 169 papers included at full text review, 57 studies were included for meta-analysis. Within the 57 included studies, 41 were in RU and 16 were in RL players. In RU, 36 studies included senior players of which 16 studies included elite players [29-37, 19, 
17, 38-42] and 21 included sub-elite players [34, 43-62]. Five studies were in junior RU players, of which three studies included elite players [63-65] and two included sub-elite players [66, 67]. In RL, 12 studies included senior players of which seven studies included elite players $[68,6,69,16,18,70,20]$ and five included sub-elite players $[71-74,20]$. Seven studies included junior RL players, of which six studies included elite players [68, $75,18,76-78]$ and only one study included sub-elite players [79]. Some studies included more than one playing standard or age group.

Meta-analysis Individual study characteristics and results for each variable can be found in supplementary document 2 . The summary effects for each variable and subgroup are provided in supplementary document 4.

\subsection{Rugby Union}

\subsubsection{Fat free mass}

Backs

Senior elite backs ( $79.2 \mathrm{~kg}, 95 \%$ CI: 76.9 to $81.4 \mathrm{~kg}, n=10)$ had a significantly higher FFM than sub-elite backs $(66.8 \mathrm{~kg}, 95 \% \mathrm{CI}: 62.9$ to $70.5 \mathrm{~kg}, n=8)(p<0.001)$. FFM was also higher in senior elite backs than junior elite backs $(63.7 \mathrm{~kg}, 95 \%$ CI: 62.3 to $65.1 \mathrm{~kg}, n=1)(p<0.001)$. The FFM of junior sub-elite backs was not assessed in any of the included studies. Sensitivity analysis revealed minor changes only, and these changes did not substantially alter the overall mean difference.

Forwards

FFM was significantly higher in senior elite forwards $(91.1 \mathrm{~kg}, 95 \% \mathrm{CI}: 88.6$ to $93.5 \mathrm{~kg}, n=10)$ than sub-elite forwards (76.3 kg, 95\% CI: 71.5 to $81.1 \mathrm{~kg}, n=8)(p<0.001)$. Senior elite forwards also had a significantly higher FFM than junior elite forwards ( $68.3 \mathrm{~kg} \mathrm{95 \%} \mathrm{CI:} 66.7$ to $69.8 \mathrm{~kg}, n=1)(p<0.001)$. The FFM of junior sub-elite forwards was not assessed in any of the included studies. Sensitivity analysis revealed minor changes only, and these changes did not substantially alter the overall mean difference

\footnotetext{
**Insert Figure $1 * *$
} 
Figure 1: Forest plot of study means and sub-group summaries (means $\pm 95 \%$ confidence intervals [CIs]) for studies evaluating FFM $(\mathrm{kg})$ in rugby union. The black circle represents the summary (mean $\pm 95 \% \mathrm{CI})$ for each sub-group. The heterogeneity of each sub-group was senior elite backs $\left(\mathrm{I}^{2}=93.9 \%, \mathrm{Q}=147.6, \tau^{2}=11.8, \mathrm{df}=\right.$ 9), senior elite forwards $\left(I^{2}=95.3 \%, Q=191.1, \tau^{2}=13.1, \mathrm{df}=9\right)$, senior sub-elite backs $\left(\mathrm{I}^{2}=95.9 \%, \mathrm{Q}=172.7\right.$, $\left.\tau^{2}=27.3, \mathrm{df}=7\right)$, and senior sub-elite forwards $\left(\mathrm{I}^{2}=96.2 \%, \mathrm{Q}=185.6, \tau^{2}=42.8, \mathrm{df}=7\right)$.

\subsubsection{Absolute fat mass}

Backs

There was no significant difference in absolute FM between senior elite backs $(11.4 \mathrm{~kg}, 95 \%$ CI: 10.2 to 12.6 $\mathrm{kg}, n=7)$ and senior sub-elite backs $(13.5 \mathrm{~kg}, 95 \% \mathrm{CI}: 8.5$ to $18.4 \mathrm{~kg}, n=3)(p=0.274)$. There was also no significant difference between senior elite backs and junior elite backs ( $10.2 \mathrm{~kg}, 95 \% \mathrm{CI}$ : 9.6 to $10.8 \mathrm{~kg}, n=1)$ $(p=0.351)$. The absolute FM of junior sub-elite backs was not assessed in any of the included studies.

Sensitivity analysis revealed that the removal of Bell (1979) from senior sub-elite backs (15.7 kg, $95 \%$ CI: 14.2 to $17.2 \mathrm{~kg}, n=2)$ caused the comparison with senior elite backs to become significant $(p<0.001)$.

\section{Forwards}

There was no significant difference in absolute FM between senior elite forwards (16.9 kg, 95\% CI: 15.7 to 18.1 $\mathrm{kg}, n=7)$ and sub-elite forwards $(21.7 \mathrm{~kg}, 95 \% \mathrm{CI}: 15.0$ to $28.4 \mathrm{~kg}, n=3)(p=0.171)$. There was no significant difference found between senior elite forwards and junior elite forwards (15.2 kg, 95\% CI: 13.7 to $16.7 \mathrm{~kg}, n=$ 1) $(p=0.080)$. The absolute FM of junior sub-elite forwards was not assessed in any of the included studies. The removal of Bell (1979) made the absolute FM of senior sub-elite forwards (24.7 kg, 95\% CI: 22.4 to 27.1 $\mathrm{kg}, n=2)$ significantly higher than senior elite forwards $(p<0.001)$.

\section{**Insert Figure 2**}

Figure 2: Forest plot of study means and sub-group summaries (means $\pm 95 \%$ confidence intervals [CIs]) for studies evaluating FM $(\mathrm{kg})$ in rugby union. The black circle represents the summary (mean $\pm 95 \% \mathrm{CI})$ for each sub-group. The heterogeneity of each sub-group was senior elite backs $\left(\mathrm{I}^{2}=74.0 \%, \mathrm{Q}=23.0, \tau^{2}=0.8, \mathrm{df}=6\right)$, senior elite forwards $\left(\mathrm{I}^{2}=71.0 \%, \mathrm{Q}=20.6, \tau^{2}=1.7, \mathrm{df}=6\right)$, senior sub-elite backs $\left(\mathrm{I}^{2}=96.5 \%, \mathrm{Q}=57.2, \tau^{2}=\right.$ $18.3, \mathrm{df}=2)$, and senior sub-elite forwards $\left(\mathrm{I}^{2}=95 \%, \mathrm{Q}=40.3, \tau^{2}=33.2 \mathrm{df}=2\right)$.

\subsubsection{Percentage fat mass}

Backs

$\%$ FM was significantly lower in senior elite backs $(11.4 \%, 95 \% \mathrm{CI}: 10.5$ to $12.3 \%, n=9)$ than senior sub-elite backs $(13.4 \%, 95 \% \mathrm{CI}: 12.0$ to $14.9 \%, n=14)(p=0.015)$. Senior elite backs also had significantly lower \%FM than junior elite backs $(14.0 \%, 95 \%$ CI: 13.4 to $14.7 \%, n=2)(p<0.001)$. There was no significant difference in 
\%FM between junior elite backs and junior sub-elite backs $(13.9 \%, 95 \%$ CI: 8.8 to $19.0 \%, n=2)(p=0.957)$.

There was no significant difference between senior sub-elite and junior sub-elite backs $(p=0.789)$. Sensitivity analysis revealed minor changes only, and these changes did not substantially alter the overall mean difference.

Forwards

\%FM was significantly lower in senior elite forwards $(15.3 \%, 95 \% \mathrm{CI}: 14.1$ to $16.5 \%, n=9)$ than senior subelite forwards $(17.7 \%, 95 \% \mathrm{CI}$ : 16.2 to $19.2 \%, n=14)(p=0.018)$. Senior elite forwards had significantly lower $\% \mathrm{FM}$ than junior elite forwards $(18.6 \%, 95 \% \mathrm{CI}: 17.7$ to $19.6 \%, n=2)(p<0.001)$. There was no significant difference in \%FM between junior elite and sub-elite forwards $(18.2 \%, 95 \% \mathrm{CI}: 10.5$ to $25.9 \%, n=2)(p=$ 0.901). There was no significant difference between senior sub-elite forwards and junior sub-elite forwards ( $p=$ $0.927)$.

\section{**Insert Figure $3 * *$}

Figure 3: Forest plot of study means and sub-group summaries (means $\pm 95 \%$ confidence intervals [CIs]) for studies evaluating $\% \mathrm{FM}$ in rugby union. The black circle represents the summary (mean $\pm 95 \% \mathrm{CI}$ ) for each sub-group. The heterogeneity of each sub-group was senior elite backs $\left(\mathrm{I}^{2}=92.4 \%, \mathrm{Q}=105.7, \tau^{2}=1.4, \mathrm{df}=8\right)$, senior elite forwards $\left(\mathrm{I}^{2}=95.4 \%, \mathrm{Q}=174.4, \tau^{2}=3.2, \mathrm{df}=8\right)$, senior sub-elite backs $\left(\mathrm{I}^{2}=93.0 \%, \mathrm{Q}=185.3, \tau^{2}=\right.$ $6.5, \mathrm{df}=13)$, senior sub-elite forwards $\left(\mathrm{I}^{2}=90.3 \%, \mathrm{Q}=134.3, \tau^{2}=7.1, \mathrm{df}=13\right)$, junior elite backs $\left(\mathrm{I}^{2}=27.5 \%\right.$, $\left.\mathrm{Q}=1.4, \tau^{2}=0.1, \mathrm{df}=1\right)$, junior elite forwards $\left(\mathrm{I}^{2}=<0.5 \%, \mathrm{Q}=0.1, \tau^{2}=<0.5, \mathrm{df}=1\right)$, junior sub-elite backs $\left(\mathrm{I}^{2}\right.$ $\left.=98.5 \%, \mathrm{Q}=68.5, \tau^{2}=13.3, \mathrm{df}=1\right)$, and junior sub-elite forwards $\left(\mathrm{I}^{2}=88.0 \%, \mathrm{Q}=8.4, \tau^{2}=27.5, \mathrm{df}=1\right)$.

\subsubsection{Sum of seven-site skinfolds}

Backs

Sum of seven-site skinfolds (7SF) was significantly lower in senior elite backs (56.4 mm, 95\% CI: 51.5 to 61.3 $\mathrm{mm}, n=5)$ than senior sub-elite backs $(68.3 \mathrm{~mm}, 95 \% \mathrm{CI}: 61.7$ to $74.8 \mathrm{~mm}, n=1)(p=0.004)$. The sum of SF7 of junior backs was not assessed in any of the included studies. Sensitivity analysis revealed minor changes only, and these changes did not substantially alter the overall mean difference.

\section{Forwards}

SF7 was significantly lower in senior elite forwards $(78.7 \mathrm{~mm}, 95 \% \mathrm{CI}: 72.3$ to $85.1 \mathrm{~mm}, n=5)$ than senior subelite forwards (99.3 mm, 95\% CI: 87.9 to $110.7 \mathrm{~mm}, n=1)(p=0.002)$. The sum of SF7 of junior forwards was not assessed in any of the included studies. Sensitivity analysis revealed minor changes only, and these changes did not substantially alter the overall mean difference. 


\section{**Insert Figure 4**}

Figure 4: Forest plot of study means and sub-group summaries (means $\pm 95 \%$ confidence intervals [CIs]) for studies evaluating SF7 (mm) in rugby union. The black circle represents the summary (mean $\pm 95 \% \mathrm{CI})$ for each sub-group. The heterogeneity of each sub-group was senior elite backs $\left(\mathrm{I}^{2}=85.5 \%, \mathrm{Q}=27.6, \tau^{2}=25.3, \mathrm{df}=4\right)$ and senior elite forwards $\left(I^{2}=73.2 \%, Q=14.9, \tau^{2}=37.8, \mathrm{df}=4\right)$.

\subsubsection{Sum of four-site skinfolds}

Backs

Sum of four-site skinfolds (4SF) was significantly lower in senior elite backs (26.4 mm, 95\% CI: 24.4 to 28.4 $\mathrm{mm}, n=1)$ than senior sub-elite backs ( $44.1 \mathrm{~mm}, 95 \% \mathrm{CI}: 40.2$ to $47.9 \mathrm{~mm}, n=2)(p=<0.001)$. The $4 \mathrm{SF}$ of junior backs was not assessed in any of the included studies. Sensitivity analysis revealed minor changes only, and these changes did not substantially alter the overall mean difference.

Forwards

4SF was significantly lower in senior elite forwards (36.2 mm, 95\% CI: 31.3 to $41.1 \mathrm{~mm}, n=1)$ than senior subelite forwards (62.5 mm, 95\% CI: 57.2 to $67.8 \mathrm{~mm}, n=2)(p=<0.001)$. The sum of 4SF of junior forwards was not assessed in any of the included studies. Sensitivity analysis revealed minor changes only, and these changes did not substantially alter the overall mean difference.

\section{$* *$ Insert Figure 5**}

Figure 5: Forest plot of study means and sub-group summaries (means $\pm 95 \%$ confidence intervals [CIs]) for studies evaluating SF4 (mm) in rugby union. The black circle represents the summary (mean $\pm 95 \% \mathrm{CI})$ for each sub-group. The heterogeneity of each sub-group was senior sub-elite backs $\left(\mathrm{I}^{2}=<0.05 \%, \mathrm{Q}=0.4, \tau^{2}=<0.05, \mathrm{df}\right.$ $=1)$ and senior sub-elite forwards $\left(\mathrm{I}^{2}=17.9 \%, \mathrm{Q}=1.2, \tau^{2}=3.3 \mathrm{df}=1\right)$.

\subsubsection{Sum of eight-site skinfolds}

Backs

Eight-site skinfolds (8SF) was significantly lower in senior elite backs $(72.5 \mathrm{~mm}, 95 \% \mathrm{CI}: 67.2$ to $77.7 \mathrm{~mm}, n=$ 2) than senior sub-elite backs ( $90.9 \mathrm{~mm}, 95 \% \mathrm{CI}: 80.3$ to $101.5 \mathrm{~mm}, n=2)(p=0.002)$. No difference was observed between senior elite backs and junior elite backs $(71.0 \mathrm{~mm}, 95 \% \mathrm{CI}: 63.1$ to $78.9 \mathrm{~mm}, n=1)(p=$ 0.766). The sum of $8 \mathrm{SF}$ of junior sub-elite backs was not assessed in any of the included studies.

Forwards 
8SF was significantly lower in senior elite forwards (102.1 mm, 95\% CI: 94.3 to $109.9 \mathrm{~mm}, n=2)$ than senior sub-elite forwards (126.9 mm, 95\% CI: 112.7 to $141.0 \mathrm{~mm}, n=2)(p=0.003)$. No difference was observed between senior elite forwards and junior elite forwards $(106.0 \mathrm{~mm}, 95 \% \mathrm{CI}$ : 93.7 to $118.4 \mathrm{~mm}, n=1)(p=$ 0.599). The sum of 8SF of junior sub-elite forwards was not assessed in any of the included studies.

\author{
$* *$ Insert Figure $6 * *$
}

Figure 6: Forest plot of study means and sub-group summaries (means $\pm 95 \%$ confidence intervals [CIs]) for studies evaluating SF8 $(\mathrm{mm})$ in rugby union. The black circle represents the summary (mean $\pm 95 \% \mathrm{CI})$ for each sub-group. The heterogeneity of each sub-group was senior elite backs $\left(\mathrm{I}^{2}<0.05 \%, \mathrm{Q}=0.8, \tau^{2}<0.01, \mathrm{df}=1\right)$, senior elite forwards $\left(\mathrm{I}^{2}<0.05 \%, \mathrm{Q}=0.7, \tau^{2}<0.001, \mathrm{df}=1\right)$, senior sub-elite backs $\left(\mathrm{I}^{2}<0.05 \%, \mathrm{Q}=0.2, \tau^{2}\right.$ $<0.01, \mathrm{df}=1)$, and senior sub-elite forwards $\left(\mathrm{I}^{2}=24.58 \%, \mathrm{Q}=1.3, \tau^{2}=26.6, \mathrm{df}=1\right)$.

\title{
3.1.7 Bone mineral content
}

Backs

There was no significant difference in BMC between senior elite backs (3732 g, 95\% CI: 3277 to $4189 \mathrm{~g}, n=5$ ) and senior sub-elite backs (3401 g, 95\% CI: 3138 to $3662 \mathrm{~g}, n=3)(p=0.215)$. The BMC of junior elite or subelite backs was not assessed in any of the included studies. Sensitivity analysis revealed that the removal of Higham et al. (2014) from senior elite backs (3982 g, 95\% CI: 3663 to $4301 \mathrm{~g}, n=4)$ caused the comparison with senior sub-elite backs to become significant $(p=0.006)$.

\section{Forwards}

There was no significant difference in BMC between senior elite forwards (4283 g, 95\% CI: 3903 to 4664 g, $n=$ 5) and senior sub-elite forwards (3998 g, 95\% CI: 3774 to $4223 \mathrm{~g}, n=3)$ ( $p=0.204)$. The BMC of junior elite or sub-elite forwards was not assessed in any of the included studies. Sensitivity analysis revealed the removal of Higham et al. (2014) from senior elite forwards (4422 g, 95\% CI: 4310 to $4534 \mathrm{~g}, n=4$ ) caused the comparison with senior sub-elite forwards to become significant $(p=0.001)$.

\section{**Insert Figure $7 * *$}

Figure 7: Forest plot of study means and sub-group summaries (means $\pm 95 \%$ confidence intervals [CIs]) for studies evaluating BMC (g) in rugby union. The black circle represents the summary (mean $\pm 95 \% \mathrm{CI})$ for each sub-group. The heterogeneity of each sub-group was senior elite backs $\left(\mathrm{I}^{2}=97.7 \%, \mathrm{Q}=175.0, \tau^{2}=263044.0, \mathrm{df}\right.$ $=4)$, senior elite forwards $\left(\mathrm{I}^{2}=96.5 \%, \mathrm{Q}=114.5, \tau^{2}=180062\right.$, df $\left.=4\right)$, senior sub-elite backs $\left(\mathrm{I}^{2}=93.5 \%, \mathrm{Q}=\right.$ $\left.30.6, \tau^{2}=49506.9, \mathrm{df}=2\right)$, and senior sub-elite forwards $\left(\mathrm{I}^{2}=90.4 \%, \mathrm{Q}=20.8, \tau^{2}=35065.5, \mathrm{df}=2\right)$. 


\subsection{Rugby league}

\subsubsection{Fat Free Mass}

Backs

FFM was significantly higher in senior elite backs $(71.5 \mathrm{~kg}, 95 \% \mathrm{CI}: 70.6$ to $72.4 \mathrm{~kg}, n=3)$ than senior sub-elite backs $(67.8 \mathrm{~kg}, 95 \% \mathrm{CI}: 66.2$ to $69.5 \mathrm{~kg}, n=2)(p<0.001)$. There was no significant difference between senior elite backs and junior elite backs $(70.3 \mathrm{~kg}, 95 \% \mathrm{CI}: 68.7$ to $71.9 \mathrm{~kg}, n=1)(p=0.200)$. The FFM of junior subelite backs was not assessed in any of the included studies. Sensitivity analysis revealed minor changes only, and these changes did not substantially alter the overall mean difference.

\section{Forwards}

FFM was significantly higher in senior elite forwards (77.2 kg, 95\% CI: 76.4 to $78.0 \mathrm{~kg}, n=3)$ than senior subelite forwards (74.7 kg, 95\% CI: 72.8 to $76.5 \mathrm{~kg}, n=2)(p=0.010)$. Senior elite forwards also had a significantly greater FFM than junior elite forwards $(73.3 \mathrm{~kg}, 95 \% \mathrm{CI}: 71.8$ to $74.8 \mathrm{~kg}, n=1)(p<0.001)$. The FFM of junior sub-elite forwards was not assessed in any of the included studies. Sensitivity analysis revealed minor changes only, and these changes did not substantially alter the overall mean difference.

\footnotetext{
$* *$ Insert Figure $8 * *$
}

Figure 8: Forest plot of study means and sub-group summaries (means $\pm 95 \%$ confidence intervals [CIs]) for studies evaluating FFM $(\mathrm{kg})$ in rugby league. The black circle represents the summary (mean $\pm 95 \% \mathrm{CI})$ for each sub-group. The heterogeneity of each sub-group was senior elite backs $\left(\mathrm{I}^{2}=75.4 \%, \mathrm{Q}=18.1 \tau^{2}=4.7, \mathrm{df}=\right.$ $2)$, senior elite forwards $\left(\mathrm{I}^{2}==40.6 \%, \mathrm{Q}=3.3, \tau^{2}=0.6, \mathrm{df}=2\right)$, senior sub-elite backs $\left(\mathrm{I}^{2}=<0.05 \%, \mathrm{Q}=0.7, \tau^{2}\right.$ $=<0.05, \mathrm{df}=1)$, and senior sub-elite forwards $\left(\mathrm{I}^{2}=<0.05 \%, \mathrm{Q}=0.5, \tau^{2}=<0.05, \mathrm{df}=1\right)$.

\subsubsection{Absolute fat mass}

Backs

Absolute FM was significantly lower in senior elite backs (12.0 kg, 95\% CI: 10.6 to $13.3 \mathrm{~kg}, n=3)$ than senior sub-elite backs ( $18.2 \mathrm{~kg}, 95 \% \mathrm{CI}: 16.2$ to $20.2 \mathrm{~kg}, n=1)(p<0.001)$. There was no significant difference in absolute FM between senior elite backs and junior elite backs (13.7 kg, 95\% CI: 12.1 to $15.3 \mathrm{~kg}, n=1)(p=$ 0.110). The absolute FM of junior sub-elite backs was not assessed in any of the included studies. Sensitivity analysis revealed minor changes only, and these changes did not substantially alter the overall mean difference

Forwards 
Absolute FM was significantly lower in senior elite forwards (15.6 kg, 95\% CI: 14.4 to $16.7 \mathrm{~kg}, n=3)$ than senior sub-elite forwards (20.1 kg, 95\% CI: 18.4 to $21.8 \mathrm{~kg}, n=1)(p<0.001)$. Senior elite forwards also had significantly lower absolute FM than junior elite forwards (19.3 kg, 95\% CI: 17.7 to $20.9 \mathrm{~kg}, n=1)(p<0.001)$. The absolute FM of junior sub-elite forwards was not assessed in any of the included studies. Sensitivity analysis revealed minor changes only, and these changes did not substantially alter the overall mean difference

\author{
**Insert Figure 9**
}

Figure 9: Forest plot of study means and sub-group summaries (means $\pm 95 \%$ confidence intervals [CIs]) for studies evaluating FM $(\mathrm{kg})$ in rugby league. The black circle represents the summary (mean $\pm 95 \% \mathrm{CI})$ for each sub-group. The heterogeneity of each sub-group was senior elite backs $\left(\mathrm{I}^{2}=87.2 \%, \mathrm{Q}=15.6, \tau^{2}=1.9, \mathrm{df}=2\right)$ and senior elite forwards $\left(\mathrm{I}^{2}=72.8 \%, \mathrm{Q}=7.4, \tau^{2}=1.1, \mathrm{df}=2\right)$.

\title{
3.2.3 Percentage fat mass
}

Backs

$\%$ FM was significantly lower in senior elite backs $(13.4 \%, 95 \% \mathrm{CI}: 11.6$ to $15.1 \%, n=4)$ than senior sub-elite backs $(17.5 \%, 95 \%$ CI: 14.6 to $20.4 \%, n=3)(p=0.020)$. No significant difference was observed between senior elite backs and junior elite backs $(13.7 \%, 95 \% \mathrm{CI}: 9.8$ to $17.7 \%, n=2)(p=0.860)$. The $\%$ FM of junior sub-elite backs was not assessed in any of the included studies. Sensitivity analysis revealed that the removal of Jones et al. (2015) from senior sub-elite backs caused the relationship with senior elite backs to become nonsignificant $(p=0.116)$.

Forwards

$\%$ FM was significantly lower in senior elite forwards $(15.8 \%, 95 \% \mathrm{CI}: 14.0 \%$ to $17.6 \%, n=4)$ than senior subelite forwards $(20.0 \%, 95 \% \mathrm{CI}: 18.8$ to $21.3 \%, n=3)(p=<0.001)$. There was no significant difference in $\% \mathrm{FM}$ between senior elite forwards and junior elite forwards $(17.9 \%, 95 \% \mathrm{CI}: 14.3$ to $21.6 \%, n=2)(p=0.310)$. The $\% \mathrm{FM}$ of junior sub-elite forwards was not assessed in any of the included studies. Sensitivity analysis revealed minor changes only, and these changes did not substantially alter the overall mean difference.

\section{**Insert Figure 10**}

Figure 10: Forest plot of study means and sub-group summaries (means $\pm 95 \%$ confidence intervals [CIs]) for studies evaluating \%FM in rugby league. The black circle represents the summary (mean $\pm 95 \% \mathrm{CI}$ ) for each sub-group. The heterogeneity of each sub-group was senior elite backs $\left(\mathrm{I}^{2}=91.3 \%, \mathrm{Q}=51.5, \tau^{2}=2.9, \mathrm{df}=3\right)$, senior sub-elite forwards $\left(\mathrm{I}^{2}=92.5 \%, \mathrm{Q}=39.8, \tau^{2}=3.2, \mathrm{df}=3\right)$, senior sub-elite backs $\left(\mathrm{I}^{2}=93.3 \%, \mathrm{Q}=30.0, \tau^{2}\right.$ $=6.0, \mathrm{df}=2)$, senior sub-elite forwards $\left(\mathrm{I}^{2}=93.5 \%, \mathrm{Q}=15.4, \tau^{2}=6.4, \mathrm{df}=2\right)$, junior elite backs $\left(\mathrm{I}^{2}=94.9 \%, \mathrm{Q}\right.$ $\left.=19.4, \tau^{2}=7.6, \mathrm{df}=1\right)$, and junior elite forwards $\left(\mathrm{I}^{2}=59.0 \%, \mathrm{Q}=15.4, \tau^{2}=6.4, \mathrm{df}=1\right)$. 


\subsubsection{Sum of four-site skinfolds}

Backs

Sum of four-site skinfolds (4SF) were not significantly different between senior elite backs (40.3 mm, $95 \%$ CI: 37.9 to $42.7 \mathrm{~mm}, n=2)$ and senior sub-elite backs ( $40.3 \mathrm{~mm}, 95 \% \mathrm{CI}: 34.4$ to $46.3 \mathrm{~mm}, n=3)(p=0.980)$.

Senior elite backs had higher 4SF than junior elite backs $(33.4 \mathrm{~mm}, 95 \% \mathrm{CI}: 30.3$ to $36.5 \mathrm{~mm}, n=3)(p=$ 0.001). There was no significant difference between junior elite backs and junior sub-elite backs $(34.2 \mathrm{~mm}, 95 \%$ CI: 32.6 to $35.8 \mathrm{~mm}, n=1)(p=0.660)$. Sensitivity analysis revealed minor changes only, and these changes did not substantially alter the overall mean difference

\section{Forwards}

4SF were not significantly different between senior elite forwards (58.4 mm, 95\% CI: 48.6 to $68.3 \mathrm{~mm}, n=2)$ and senior sub-elite forwards $(50.6 \mathrm{~mm}, 95 \% \mathrm{CI}: 47.8$ to $53.4 \mathrm{~mm}, n=3)(p=0.130)$. Senior elite forwards had higher 4SF than junior elite forwards $(39.7 \mathrm{~mm}, 95 \% \mathrm{CI}: 32.2$ to $47.1 \mathrm{~mm}, n=3)(p=0.003)$. Junior elite forwards had significantly lower 4SF than junior sub-elite forwards (48.4 mm, 95\% CI, 45.7 to $51.2 \mathrm{~mm}, n=1)$ $(p=0.030)$. Sensitivity analysis revealed minor changes only, and these changes did not substantially alter the overall mean difference.

\footnotetext{
**Insert Figure $11 * *$
}

Figure 11: Forest plot of study means and sub-group summaries (means $\pm 95 \%$ confidence intervals [CIs]) for studies evaluating SF4 (mm) in rugby league. The black circle represents the summary (mean $\pm 95 \% \mathrm{CI})$ for each sub-group. The heterogeneity of each sub-group was senior elite backs $\left(\mathrm{I}^{2}=14.0 \%, \mathrm{Q}=1.2, \tau^{2}=0.6, \mathrm{df}=\right.$ $1)$, senior elite forwards $\left(\mathrm{I}^{2}=73.9 \%, \mathrm{Q}=3.8, \tau^{2}=38.0, \mathrm{df}=1\right)$, senior sub-elite backs $\left(\mathrm{I}^{2}=96.1 \%, \mathrm{Q}=25.9, \tau^{2}\right.$ $=29.6, \mathrm{df}=2)$, senior sub-elite forwards $\left(\mathrm{I}^{2}=81.9 \%, \mathrm{Q}=11.1, \tau^{2}=4.8, \mathrm{df}=2\right)$, junior elite backs $\left(\mathrm{I}^{2}=87.3 \%\right.$, $\left.\mathrm{Q}=15.7, \tau^{2}=5.1, \mathrm{df}=2\right)$, and junior elite forwards $\left(\mathrm{I}^{2}=90.7 \%, \mathrm{Q}=21.5, \tau^{2}=35.8, \mathrm{df}=2\right)$.

\subsubsection{Sum of seven-site skinfolds}

Backs

Sum of seven-site skinfolds (7SF) were not significantly different between senior elite backs (54.0 mm, $95 \% \mathrm{CI}$ : 51.1 to $57.0 \mathrm{~mm}, n=2)$ and junior elite backs $(57.1 \mathrm{~mm}, 95 \% \mathrm{CI}: 54.2$ to $59.9 \mathrm{~mm}, n=2)(p=0.535)$. The $7 \mathrm{SF}$ of senior and junior sub-elite backs was not assessed in any of the included studies.

Forwards 
7SF were not significantly different between senior elite forwards (62.8 mm, 95\% CI: 60.1 to $65.4 \mathrm{~mm}, n=2)$ and junior elite forwards $(75.7 \mathrm{~mm}, 95 \% \mathrm{CI}: 44.7$ to $106.6 \mathrm{~mm}, n=2)(p=0.495)$. The $7 \mathrm{SF}$ of senior and junior sub-elite backs was not assessed in any of the included studies.

\author{
**Insert Figure 12**
}

Figure 12: Forest plot of study means and sub-group summaries (means $\pm 95 \%$ confidence intervals [CIs]) for studies evaluating SF7 (mm) in rugby league. The black circle represents the summary (mean $\pm 95 \% \mathrm{CI})$ for each sub-group. The heterogeneity of each sub-group was senior elite backs $\left(\mathrm{I}^{2}=60.9 \%, \mathrm{Q}=2.6, \tau^{2}=7.3, \mathrm{df}=\right.$ $1)$, senior elite forwards $\left(I^{2}=92.9 \%, Q=14.0, \tau^{2}=51.97, \mathrm{df}=1\right)$, junior elite backs $\left(\mathrm{I}^{2}=96.1 \%, \mathrm{Q}=25.8, \tau^{2}=\right.$ 114.2, $\mathrm{df}=1)$, and junior elite forwards $\left(\mathrm{I}^{2}=97.7 \%, \mathrm{Q}=44.3, \tau^{2}=488.0, \mathrm{df}=1\right)$.

\title{
3.2.6 Bone mineral content
}

Backs

BMC was significantly higher in senior elite backs (4160 g, 95\% CI: 4076 to $4245 \mathrm{~g}, n=2)$ than senior sub-elite backs (3971 g, 95\% CI: 3848 to $4094 \mathrm{~g}, n=1)(p=0.010)$. There was no difference between senior elite backs and junior elite backs (4009 g, 95\% CI: 3870 to $4147 \mathrm{~g}, n=1)(p=0.070)$. The BMC of junior sub-elite backs was not assessed in any of the included studies. Sensitivity analysis revealed minor changes only, and these changes did not substantially alter the overall mean difference

\section{Forwards}

There was a trend towards BMC being higher in senior elite forwards ( $4469 \mathrm{~g}, 95 \% \mathrm{CI}: 4381$ to $4557 \mathrm{~g}, n=2$ ) than senior sub-elite forwards (4302 g, 95\% CI: 4151 to $4453 \mathrm{~g}, n=1)(p=0.060)$. Senior elite forwards had significantly greater BMC than junior elite forwards (4157 g, 95\% CI: 4004 to $4310 \mathrm{~g}, n=1)(p<0.001)$. The BMC of junior sub-elite forwards was not assessed in any of the included studies. Sensitivity analysis revealed minor changes only, and these changes did not substantially alter the overall mean difference

\section{**Insert Figure 13**}

Figure 13: Forest plot of study means and sub-group summaries (means $\pm 95 \%$ confidence intervals [CIs]) for studies evaluating BMC $(\mathrm{g})$ in rugby league. The black circle represents the summary (mean $\pm 95 \% \mathrm{CI})$ for each sub-group. The heterogeneity of each sub-group was senior elite backs $\left(\mathrm{I}^{2}=<0.05 \%, \mathrm{Q}=0.6, \tau^{2}=<0.05, \mathrm{df}=1\right)$ and senior elite forwards $\left(\mathrm{I}^{2}=7.1, \mathrm{Q}=0.3, \tau^{2}=<0.05, \mathrm{df}=1\right)$

\section{Discussion}

\subsection{Overview of the meta-analysis}


The purpose of this meta-analysis was to provide a comprehensive overview of body composition across RU and RL and to investigate differences between age groups and playing standards. The primary outcomes of the study revealed that FFM is higher in senior than junior players (age), and elite than non-elite (standard) in RU players and RL forwards. No difference in FFM was found in RL elite backs (senior vs. junior). The findings for FM were less clear, with no differences found between age or standard in either RU positional group. In RL, senior elite players had lower FM than sub-elite, with no difference found between senior and junior elite backs, but senior forwards had lower FM than junior elite forwards. Increases in FFM and negligible differences in FM, resulted in senior elite players of both rugby codes and positional groups having reduced \%FM. No differences were found between senior elite or sub-elite players for BMC, apart from RL backs where senior elite had higher BMC than sub-elite players. Consequently, FFM accrual may be a key distinguishing factor between age and playing standard in RU and RL as opposed to other body composition measures (FM, BMC, or $\% \mathrm{FM})$.

\subsection{Fat-free mass}

The findings of this meta-analysis suggest that RU senior elite forwards and backs have significantly higher FFM than senior sub-elite and junior elite forwards and backs. Similarly, rugby league senior elite forwards had significantly higher FFM than senior sub-elite and junior elite forwards, while RL senior elite backs had significantly higher amounts of FFM than senior sub-elite, but not junior elite backs. The explanation for the reported differences in FFM is likely due to elite senior players being full-time professionals, whereas sub-elite

players are more likely to be part-time [80]. This allows elite players to dedicate a greater amount of time to training, nutrition and other lifestyle factors which are likely to benefit FFM accrual [20]. Furthermore, access to full time club practitioners (strength and conditioning coaches / nutritionists) is more likely within a professional environment [74]. Alternatively, it must be acknowledged that elite senior players may possess a genetic advantage for the accrual of FFM, which has enabled them to gain elite status. The cross-sectional nature of the data included in this study means that direct causal relationships cannot be established, but it is most likely to be due to a combination of both genetic advantage and advanced training regimes.

The higher FFM in elite senior RL and RU forwards is expected to provide an advantage during match play. Forwards in both codes are required to undertake a large number of collisions per game $[14,81]$, in which they are required be dominant and advance by as many metres as possible. Consequently, higher amounts of FFM 
should allow players to exert greater forces [9], particularly when static (scrummaging) or wrestling (in a ruck or tackle). In non-static exertions of force, linear momentum, the product of mass and velocity, also has logical benefits upon collisions [33, 8]. An increase in FFM and subsequent increase in overall mass, would increase momentum on the condition that velocity remains constant. This is suggested to improve ball carrying at the gain line, increasing the ability to overcome opposing defenders, and greater impact forces in tackles [82]. It is logical to assume that an increase in FFM as opposed to FM, would not negatively affect velocity [8], however, this remains speculative without knowing a players acceleration ability [20].

Senior elite RU players and RL forwards had significantly higher amounts of FFM than junior elite players of the same position. A key role of professional rugby academies is to facilitate the transition of players to the senior elite squads. It is essential to physically prepare academy players for increased training and match demands at senior level $[83,84]$. The lower levels of FFM in junior elite players may be due to musculoskeletal immaturity, minimal time within the academy, or low relative training age [76]. However, it is also likely to be hampered by uniquely high energy requirements [85-87], which are the result of numerous training sessions and matches per week [88], combined with growth and other life demands (full-time education etc.). Collisions within games and training may further hinder FFM accrual due to elevations in resting metabolic rate for up to 72 hours after collision-based activity, thereby challenging the attainment of a positive energy balance [89]. Hypertrophy is multifaceted but an appropriate stimulus from resistance training is undoubtedly required [90], yet, this is often restricted due to time and facilities for adolescent rugby players [88]. Accordingly, it is imperative that practitioners and coaches are aware of the unique energetic demands placed upon professional young collision-sport athletes during intensified training periods in order to provide an appropriate stimulus and nutritional plan for FFM development.

\subsection{Fat mass}

Absolute FM did not differ between age or standard in RU for either positional group. These findings suggest that the higher body mass of senior elite players [91] are likely to be the result of greater FFM, rather than differences in FM. Consequently, coaches and practitioners may benefit most from a focus on FFM accrual, rather than FM reductions. This is an important consideration based on the frequent use of body fat targets for players and previous concerns over the effects of FM on acceleration and energetic cost of movement [92, 93]. 
In RL, senior elite backs and forwards had lower FM than senior sub-elite players, and senior elite forwards had lower FM than junior elite forwards. A greater overall body mass may have potential benefits in collisions due to an increased linear momentum, however, increased FM may also negatively affect velocity and acceleration, causing detrimental effects upon momentum [33, 95]. Given the high intensity activities and locomotor demands of RL match play [96], a higher amount of FM may negatively affect other match demands. Junior RL forwards had an increased amount of FM compared to senior elite forwards, which may have desirable consequences on momentum and successful collisions in the absence of sufficient FFM development [18] [33, 82]. However, an increase in match demands from academy to professional RL [97] as well as continued development of FFM [18] may result in the increased FM becoming detrimental as players progress from junior elite (academy) to senior elite (professional), thus the shift to lower levels of FM.

Senior elite players had greater 4SF than junior elite players for both positional groups, and junior elite forwards had lower 4SF than junior sub-elite forwards. However, no difference was found in 7SF between senior playing standards or elite playing standards for either positional group. Skinfold anthropometry is often used as an applied measure of body composition due to the low cost and speed of measurement [98]. Typically, within RL research 4SF is used, as a measure of subcutaneous fat at four specific points and often a proxy of FM [99]. Results from this meta-analysis suggest that FM decreases from senior sub-elite to elite playing standard, however, this is contrary to the findings of 4SF. Furthermore, FM decreases from junior to senior elite forwards, also contrary to the findings of $4 \mathrm{SF}$ and $7 \mathrm{SF}$. Therefore, this may suggest that $4 \mathrm{SF}$ and $7 \mathrm{SF}$ may not be an appropriate measure of body composition in RL. The accuracy of skinfold anthropometry is inherently linked to the skill and experience of the practitioner[100], which may also explain the poor relationship between SF and FM.

In RU, senior elite players had significantly less $8 \mathrm{SF}, 7 \mathrm{SF}$, and 4SF than senior sub-elite of both positional groups. Results from this meta-analysis observed no difference in absolute FM between RU senior elite and subelite. Subsequently, this would suggest skinfolds are not an appropriate measure of absolute FM in senior RU players. Skinfold anthropometry does offer an applied measure of monitoring body composition [98], however, practitioners should appreciate that the sum of skinfold measures may not act as an accurate assessment of absolute FM in senior RU players. 


\subsection{Percentage fat mass}

In RU, senior elite players had lower \%FM than junior elite and senior sub-elite players. Despite having negligible differences in absolute FM between age and playing standard, an increased amount of FFM in senior elite cause a reduced percentage of FM to overall mass. In RL, \%FM was significantly lower in senior elite than sub-elite players. No difference was found between junior or senior elite in either backs or forwards. Although not significant, \%FM did display a trend towards being lower in senior over junior elite forwards. Percentage FM is often used within an applied rugby environment [101] as it can be calculated from via skinfold equations [102]. However, the ability of skinfold equations to accurately estimate \%FM within a rugby population has been questioned [103]. Subsequently, practitioners are encouraged to determine absolute measures of body composition and, where possible, prioritise the assessment of FFM. Ideally, this would be through criterion assessment methods (DXA) ensuring best practise protocol of assessment [104].

\subsection{Bone mineral content}

Bone mineral content was only assessed in a small number of included studies due to the required assessment technique (DXA). No clear differences were found in BMC between senior standards in either RU positional group. RL senior elite backs had greater amount of BMC than senior sub-elite backs, and senior elite forwards had greater amounts of BMC than junior elite forwards. A high BMC is desirable as it is likely to restrict the possibility of skeletal fractures [105]. Increased FFM is associated with greater BMC due to greater torque being acted upon the bone [11]. Although senior elite players had considerably greater FFM than sub-elite players, it would appear that a ceiling may exist to the amount FFM and rugby training that can influence BMC. Negligible differences within senior populations (excluding RL backs) is also likely due to both groups having reached skeletal maturity [106]. This would suggest that rugby training assists in the development of BMC. Given that limited studies exist within junior RU and RL that measure BMC, this represents a direction for future research.

\section{Limitations}

This is the first systematic review and meta-analysis to comprehensively analyse body composition within both rugby codes, however, some limitations should be acknowledged. Research into body composition in rugby is an emerging field and gaps within the literature still exist, particularly within junior players. This meta-analysis aims to counteract this by combining papers for analysis, however, the statistical power of the analysis must be considered when interpreting the results. As few as one study were included in some subgroups for analysis, and 
therefore may be underpowered. Included studies used varying methods to assess body composition, despite the potential for variance between methods, a meta-analysis would not have been possible without the combination of them. It must be assumed that necessary steps were taken to ensure methodological rigor in each included paper. Studies were excluded if data were not split by position, due to the known differences between backs and forwards. This potentially excluded some literature within the area of study. Finally, despite an extensive search returning 3,542 records, it cannot be guaranteed that the search was completely exhaustive of the relevant literature, however, reference lists from relevant reviews were also assessed for missing papers.

\section{Conclusion}

This meta-analysis examined the differences in body composition by age and playing standard in both rugby codes. FFM was found to be significantly higher in senior elite cohorts than senior sub-elite or junior elite cohorts for both codes and playing positions, except RL backs. In RU, insignificant differences were found in FM for all groups between age and playing standard. In RL, senior elite forwards had reduced FM compared to senior sub-elite and junior elite forwards. In parallel with these findings, increased FFM in senior elite groups caused a reduced \%FM in comparisons to sub-elite or junior elite groups. This review highlights the importance of FFM as the main distinguishing factor in body composition between age groups and playing standard in both codes. Consequently, the accretion of FFM should be prioritised by practitioners and coaches working with athletes who wish to transition to senior elite playing standards.

\section{Practical recommendations}

1. Fat free mass appears to be a key body composition variable in distinguishing between playing level and age groups in RU and RL. This is likely due to the relationship between body composition, physical qualities and the match demands of both rugby codes.

2. Practitioners and coaches should be mindful around the importance of FFM and conscious that FM may be less important.

3. Dieticians \& Sports Nutritionists should consider how best to augment FFM development. Considering the increased metabolic costs of a collision sport and how to maximise nutritional intake through behavioural \& nutritional strategies. 
Acknowledgements and decelerations:

No sources of funding were used to assist in the preparation of this paper. No author has any conflict of interest relevant to the content of this paper.

References:

1. Till K, Scantlebury S, Jones B. Anthropometric and Physical Qualities of Elite Male Youth Rugby League Players. Sports medicine (Auckland, NZ). 2017. doi:10.1007/s40279-017-0745-8.

2. Till K, Weakley J, Read DB, Phibbs P, Darrall-Jones J, Roe G et al. Applied Sport Science for Male Age-Grade Rugby Union in England. Sports Medicine-Open. 2020;6(1):1-20.

3. Whitehead S, Till K, Weaving D, Jones B. The Use of Microtechnology to Quantify the Peak Match Demands of the Football Codes: A Systematic Review. Sports Medicine. 2018;48(11):2549-75.

4. McLellan CP, Lovell DI. Performance analysis of professional, semiprofessional, and junior elite rugby league match-play using global positioning systems. The Journal of Strength \& Conditioning Research. 2013;27(12):3266-74.

5. Read DB, Till K, Beasley G, Clarkson M, Heyworth R, Lee J et al. Maximum running intensities during English academy rugby union match-play. Science and Medicine in Football. 2019;3(1):43-9.

6. Meir R, Newton R, Curtis E, Fardell M, Butler B. Physical fitness qualities of professional rugby league football players: determination of positional differences. The Journal of Strength \& Conditioning Research. 2001;15(4):450-8.

7. Gabbett TJ, Jenkins DG, Abernethy B. Relationships between physiological, anthropometric, and skill qualities and playing performance in professional rugby league players. Journal of sports sciences. 2011;29(15):1655-64.

8. Baker DG, Newton RU. Comparison of lower body strength, power, acceleration, speed, agility, and sprint momentum to describe and compare playing rank among professional rugby league players. The Journal of Strength \& Conditioning Research. 2008;22(1):153-8.

9. Taber CB, Vigotsky A, Nuckols G, Haun CT. Exercise-Induced Myofibrillar Hypertrophy is a Contributory Cause of Gains in Muscle Strength. Sports Medicine. 2019;49(7):993-7.

10. Darrall-Jones J, Roe G, Carney S, Clayton R, Phibbs P, Read D et al. The effect of body mass on the 30-15 intermittent fitness test in rugby union players. International journal of sports physiology and performance. 2016;11(3):400-3.

11. Vuori IM. Dose-response of physical activity and low back pain, osteoarthritis, and osteoporosis. Medicine \& Science in Sports \& Exercise. 2001;33(6, Suppl):S551-S86. doi:10.1097/00005768200106001-00026.

12. Till K, Scantlebury S, Jones B. Anthropometric and Physical Qualities of Elite Male Youth Rugby League Players. Sports Medicine. 2017;47(11):2171-86.

13. Read D, Weaving D, Phibbs P, Darrall-Jones J, Roe G, Weakley J et al. Movement and physical demands of school and university rugby union match-play in England. BMJ open sport \& exercise medicine. 2017;2(1):e000147.

14. Weaving D, Sawczuk T, Williams S, Scott T, Till K, Beggs $C$ et al. The peak duration-specific locomotor demands and concurrent collision frequencies of European Super League rugby. Journal of Sports Sciences. 2019;37(3):322-30.

15. Whitehead S, Till K, Weaving D, Hunwicks R, Pacey R, Jones B. Whole, half and peak running demands during club and international youth rugby league match-play. Science and Medicine in Football. 2019;3(1):63-9.

16. Morehen JC, Routledge HE, Twist C, Morton JP, Close GL. Position specific differences in the anthropometric characteristics of elite European Super League rugby players. European journal of sport science. 2015;15(6):523-9. 
17. Zemski AJ, Slater GJ, Broad EM. Body composition characteristics of elite Australian rugby union athletes according to playing position and ethnicity. Journal of Sports Sciences. 2015;33(9):970-8. 18. Till K, Jones B, O'Hara J, Barlow M, Brightmore A, Lees M et al. Three-Compartment Body Composition in Academy and Senior Rugby League Players. International Journal of Sports Physiology \& Performance. 2016;11(2):191-6.

19. Smart DJ, Hopkins WG, Gill ND. Differences and changes in the physical characteristics of professional and amateur rugby union players. The Journal of Strength \& Conditioning Research. 2013;27(11):3033-44.

20. Jones B, Till K, Barlow M, Lees M, O'Hara JP, Hind K. Anthropometric and Three-Compartment Body Composition Differences between Super League and Championship Rugby League Players: Considerations for the 2015 Season and Beyond. PloS one. 2015;10(7):e0133188. doi:10.1371/journal.pone.0133188.

21. Stroup DF, Berlin JA, Morton SC, Olkin I, Williamson GD, Rennie D et al. Meta-analysis of observational studies in epidemiology: a proposal for reporting. Meta-analysis Of Observational Studies in Epidemiology (MOOSE) group. JAMA. 2000;283(15):2008-12.

22. Swann C, Moran A, Piggott D. Defining elite athletes: Issues in the study of expert performance in sport psychology. Psychology of Sport and Exercise. 2015;16(Part 1):3-14.

doi:10.1016/j.psychsport.2014.07.004.

23. Downs SH, Black N. The feasibility of creating a checklist for the assessment of the methodological quality both of randomised and non-randomised studies of health care interventions. Journal of Epidemiology \& Community Health. 1998;52(6):377-84.

24. Hozo SP, Djulbegovic B, Hozo I. Estimating the mean and variance from the median, range, and the size of a sample. BMC medical research methodology. 2005;5(1):13.

25. Cumpston M, Li T, Page MJ, Chandler J, Welch VA, Higgins JP et al. Updated guidance for trusted systematic reviews: a new edition of the Cochrane Handbook for Systematic Reviews of Interventions. The Cochrane Database Of Systematic Reviews. 2019;10:ED000142. doi:10.1002/14651858.ED000142.

26. Higgins J, Green S, Collaboration C. Cochrane handbook for systematic reviews of interventions Wiley. Chichester, England. 2008.

27. Higgins JP, Thompson SG, Spiegelhalter DJ. A re-evaluation of random-effects meta-analysis. Journal of the Royal Statistical Society: Series A (Statistics in Society). 2009;172(1):137-59.

28. Higgins JPT, Thompson SG, Deeks JJ, Altman DG. Measuring inconsistency in meta-analyses. BMJ (Clinical Research Ed). 2003;327(7414):557-60.

29. Baker JS, Davies B. RESISTIVE FORCE SELECTION DURING BRIEF CYCLE ERGOMETER EXERCISE: IMPLICATIONS FOR POWER ASSESSMENT IN INTERNATIONAL RUGBY UNION PLAYERS. Journal of Exercise Physiology Online. 2004;7(3).

30. Bradley WJ, Cavanagh BP, Douglas W, Donovan TF, Morton JP, Close GL. Quantification of training load, energy intake, and physiological adaptations during a rugby preseason: a case study from an elite European rugby union squad. The Journal of Strength \& Conditioning Research. 2015;29(2):534-44.

31. Duthie G, Pyne D, Hopkins W, Livingstone S, Hooper S. Anthropometry profiles of elite rugby players: quantifying changes in lean mass. British journal of sports medicine. 2006;40(3):202-7. 32. Fontana FY, Colosio A, De Roia GF, Da Lozzo G, Pogliaghi S. Anthropometrics of Italian senior male rugby union players: from elite to second division. International Journal of Sports Physiology and Performance. 2015;10(6):674-80.

33. Higham DG, Pyne D, Anson J, Dziedzic C, Slater G. Distribution of fat, non-osseous lean and bone mineral mass in international rugby union and rugby sevens players. International journal of sports medicine. 2014;35(07):575-82.

34. Jones TW, Keane K, Smith A, Dent J, McShane K, Payne T et al. Which anthropometric and lower body power variables are predictive of professional and amateur playing status in male rugby union players? International Journal of Sports Science \& Coaching. 2019;14(1):82-90. 
35. Lees MJ, Oldroyd B, Jones B, Brightmore A, O'Hara JP, Barlow MJ et al. Three-compartment body composition changes in professional rugby union players over one competitive season: a team and individualized approach. Journal of Clinical Densitometry. 2017;20(1):50-7.

36. Scott AC, Roe N, Coats AJ, Piepoli MF. Aerobic exercise physiology in a professional rugby union team. International journal of cardiology. 2003;87(2-3):173-7.

37. Smart D, Hopkins WG, Quarrie KL, Gill N. The relationship between physical fitness and game behaviours in rugby union players. European journal of sport science. 2014;14(sup1):S8-S17.

38. Zemski AJ, Keating SE, Broad EM, Slater GJ. Longitudinal Changes in Body Composition Assessed Using DXA and Surface Anthropometry Show Good Agreement in Elite Rugby Union Athletes. International journal of sport nutrition and exercise metabolism. 2018:1-25.

doi:10.1123/ijsnem.2018-0019.

39. Zemski AJ, Keating SE, Broad EM, Marsh DJ, Hind K, Slater GJ. Pre-Season Body Composition Adaptations in Elite Caucasian and Polynesian Rugby Union Athletes. International journal of sport nutrition and exercise metabolism. 2018:1-24. doi:10.1123/ijsnem.2018-0059.

40. Zemski AJ, Keating SE, Broad EM, Marsh DJ, Slater GJ. Abdominal adiposity distribution in elite rugby union athletes using magnetic resonance imaging. Sport Sciences for Health. 2019;15(1):99107.

41. Brooks JHM, Fuller CW, Kemp SPT, Reddin DB. A prospective study of injuries and training amongst the England 2003 Rugby World Cup squad. British journal of sports medicine. 2005;39(5):288-93.

42. Ingle L, Nirmalendran R. Detraining effect of the post-season on selected aerobic and anaerobic performance variables in national league rugby union players: a focus on positional status. 2010.

43. Ball S, Halaki M, Sharp T, Orr R. Injury patterns, physiological profile, and performance in university rugby union. International journal of sports physiology and performance. 2018;13(1):6974.

44. Bell W, Evans W, Cobner D, Eston R. The regional placement of bone mineral mass, fat mass, and lean soft tissue mass in young adult Rugby Union players. Ergonomics. 2005;48(11-14):1462-72.

45. Bell W, Evans W, Cobner D, Eston R, editors. Whole-body and regional bone mineral density and bone mineral mass in rugby union players: comparison of forwards, backs and controls.

Kinanthropometry VIII-Proceedings of the 8th International Conference for the Advancement of Kinanthropometry (ISAK). London: Routledge; 2003.

46. Bell W, Cobner D, Evans W. Prediction and validation of fat-free mass in the lower limbs of young adult male Rugby Union players using dual-energy X-ray absorptiometry as the criterion measure. Ergonomics. 2000;43(10):1708-17.

47. Bell W. Body composition of rugby union football players. British journal of sports medicine. 1979;13(1):19-23.

48. Carlson BR, Carter JL, Patterson P, Petti K, Orfanos SM, Noffal GJ. Physique and motor performance characteristics of US national rugby players. Journal of Sports Sciences. 1994;12(4):40312.

49. Cruz-Ferreira AMd, Ribeiro CAF. Anthropometric and physiological profile of Portuguese rugby players-part I: comparison between athletes of different position groups. Revista Brasileira de Medicina do Esporte. 2013;19(1):48-51.

50. Elloumi M, Ounis OB, Courteix D, Makni E, Sellami S, Tabka Z et al. Long-term rugby practice enhances bone mass and metabolism in relation with physical fitness and playing position. Journal of bone and mineral metabolism. 2009;27(6):713-20.

51. Gamage J, Attanayake D, Subasinghe P. Physique limitation in rugby: Anthropometric and physiological evaluation of Sri Lankan national rugby players compared to international counterparts. Journal of Science and Medicine in Sport. 2015;19:e40.

52. Mashiko T, Umeda T, Nakaji S, Sugawara K. Effects of exercise on the physical condition of college rugby players during summer training camp. British journal of sports medicine.

2004;38(2):186-90. 
53. Gayol Flores MF, Sillero Quintana M. Características Antropométricas y la Ingesta Dietética de los Jugadores de la División de Honor y División de Honor B de un Club de Rugby Español-Ciencias del Ejercicio. Kronos. 2019;18(1).

54. Imamura H, lide K, Yoshimura Y, Kumagai K, Oshikata R, Miyahara K et al. Nutrient intake, serum lipids and iron status of colligiate rugby players. Journal of the International Society of sports Nutrition. 2013;10(1):9.

55. Infante J, Reyes C, Ramos M, Rayo J, Lorente R, Serrano J et al. The usefulness of densitometry as a method of assessing the nutritional status of athletes. Comparison with body mass index. Revista Española de Medicina Nuclear e Imagen Molecular (English Edition). 2013;32(5):281-5.

56. Jardine T, Wiggins TM, Myburgh KH. Physiological characteristics of rugby players including muscle glycogen content and muscle fibre composition. South African Medical Journal. 1988;73(9):529-32.

57. Jarvis S, Sullivan LO, Davies B, Wiltshire H, Baker JS. Interrelationships between measured running intensities and agility performance in subelite rugby union players. Research in Sports Medicine. 2009;17(4):217-30.

58. La Monica MB, Fukuda DH, Miramonti AA, Beyer KS, Hoffman MW, Boone CH et al. Physical differences between forwards and backs in American collegiate rugby players. Journal of strength and conditioning research. 2016;30(9):2382-91.

59. Maud PJ, Shultz BB. The US national rugby team: a physiological and anthropometric assessment. The Physician and Sportsmedicine. 1984;12(9):86-99.

60. Oprean A, Cojocariu A, Ungurean B. Mass and body composition particularities of rugby compartments. Timisoara Physical Education and Rehabilitation Journal. 2014;7(13):52-7.

61. Rossi L, dos Santos FG, Leão L. Avaliação antropométrica e da desidratação de atletas de alto nível de rúgbi. Brazilian Journal of Biomotricity. 2013;7(1):14-20.

62. Garcia M, Martinez-Moreno JM, Reyes-Ortiz A, Suarez Moreno-Arrones L, Garcia AA, Garciacaballero M. Changes in body composition of high competition rugby players during the phases of a regular season; influence of diet and exercise load. Nutricion hospitalaria.

2014;29(4):913-21. doi:10.3305/nh.2014.29.4.7227.

63. Darrall-Jones JD, Jones B, Till K. Anthropometric and physical profiles of English academy rugby union players. The Journal of Strength \& Conditioning Research. 2015;29(8):2086-96.

64. Durcan L, Coole A, McCarthy E, Johnston C, Webb M, O'Shea F et al. The prevalence of patellar tendinopathy in elite academy rugby: a clinical and imaging study. Journal of Science and Medicine in Sport. 2014;17(2):173-6.

65. Delahunt E, Byrne RB, Doolin RK, Mclnerney RG, Ruddock CTJ, Green BS. Anthropometric profile and body composition of Irish adolescent rugby union players aged 16-18. Journal of strength and conditioning research. 2013;27(12):3252-8. doi:10.1519/JSC.0b013e3182915ea6.

66. Marx A, Carvalhaes MFM, Ferreira SA, Mezalira FM, Queiroga MR. Desempenho físico e perfil antropométrico de atletas juvenis de Rugby. RBPFEX-Revista Brasileira de Prescrição e Fisiologia do Exercício. 2019;12(80):1069-77.

67. Walsh M, Cartwright L, Corish C, Sugrue S, Wood-Martin R. The body composition, nutritional knowledge, attitudes, behaviors, and future education needs of senior schoolboy rugby players in Ireland. International Journal Of Sport Nutrition And Exercise Metabolism. 2011;21(5):365-76.

68. Ballard DA. POSITIONAL BENCHMARKING AND TEAM SELECTION BASED ON PHYSICAL QUALITIES IN ELITE RUGBY LEAGUE. Journal of Australian Strength \& Conditioning. 2016;24(5):6-14.

69. Meir RA. Seasonal changes in estimates of body composition in professional rugby league players. Sport Health. 1993;11(4):27.

70. Lundy B, O'Connor H, Pelly F, Caterson I. Anthropometric characteristics and competition dietary intakes of professional rugby league players. International journal of sport nutrition and exercise metabolism. 2006;16(2):199-213.

71. Gabbett T, Kelly J, Pezet T. A comparison of fitness and skill among playing positions in sub-elite rugby league players. Journal of science and medicine in sport. 2008;11(6):585-92. 
72. Gabbett TJ. A comparison of physiological and anthropometric characteristics among playing positions in sub-elite rugby league players. Journal of Sports Sciences. 2006;24(12):1273-80.

73. Gabbett TJ. Physiological and anthropometric characteristics of amateur rugby league players. British journal of sports medicine. 2000;34(4):303-7.

74. Morgan PJ, Callister R. Effects of a preseason intervention on anthropometric characteristics of semiprofessional rugby league players. The Journal of Strength \& Conditioning Research.

2011;25(2):432-40.

75. Cheng HL, O'Connor H, Kay S, Cook R, Parker H, Orr R. Anthropometric characteristics of

Australian junior representative rugby league players. Journal of science and medicine in sport.

2014;17(5):546-51.

76. Till K, Jones BEN, Emmonds S, Tester E, Fahey J, Cooke C. SEASONAL CHANGES IN

ANTHROPOMETRIC AND PHYSICAL CHARACTERISTICS WITHIN ENGLISH ACADEMY RUGBY LEAGUE

PLAYERS. Journal of Strength \& Conditioning Research. 2014;28(9):2689-96.

77. Till K, Cobley S, O'Hara J, Chapman C, Cooke C. Anthropometric, physiological and selection characteristics in high performance UK junior rugby league players. Talent Development and Excellence. 2010;2(2):193-207.

78. Till K, Cobley S, O'Hara J, Chapman C, Cooke C. A longitudinal evaluation of anthropometric and fitness characteristics in junior rugby league players considering playing position and selection level. Journal of Science and Medicine in Sport. 2013;16(5):438-43.

79. Gabbett T. A comparison of physiological and anthropometric characteristics among playing positions in junior rugby league players. British Journal of Sports Medicine. 2005;39(9):675-80.

80. Baker D. Comparison of upper-body strength and power between professional and college-aged rugby league players. Journal of Strength and Conditioning Research. 2001;15(1):30-5.

81. Roe G, Halkier M, Beggs C, Till K, Jones B. The use of accelerometers to quantify collisions and running demands of rugby union match-play. International Journal of Performance Analysis in Sport. 2016;16(2):590-601.

82. Till K, Jones BEN, Darrall-Jones J, Emmonds S, Cooke C. LONGITUDINAL DEVELOPMENT OF ANTHROPOMETRIC AND PHYSICAL CHARACTERISTICS WITHIN ACADEMY RUGBY LEAGUE PLAYERS. Journal of Strength \& Conditioning Research. 2015;29(6):1713-22.

83. Black GM, Gabbett TJ. Repeated high-intensity-effort activity in elite and semielite rugby league match play. International journal of sports physiology and performance. 2015;10(6):711-7.

84. Cunningham DJ, Shearer DA, Drawer S, Pollard B, Eager R, Taylor N et al. Movement demands of elite under-20s and senior international rugby union players. PloS one. 2016;11(11):e0164990.

85. Smith DR, King RFGJ, Duckworth LC, Sutton L, Preston T, O'Hara JP et al. Energy expenditure of rugby players during a 14-day in-season period, measured using doubly labelled water. European Journal Of Applied Physiology. 2018;118(3):647-56. doi:10.1007/s00421-018-3804-4.

86. Costello N, Deighton K, Preston T, Matu J, Rowe J, Jones B. Are professional young rugby league players eating enough? Energy intake, expenditure and balance during a pre-season. European journal of sport science. 2019;19(1):123-32.

87. Costello N, Deighton K, Dalton-Barron N, Whitehead S, McLaren S, Jones B. Three-day changes in resting metabolism after a professional young rugby league match. Sport Performance \& Science Reports. 2019.

88. Phibbs PJ, Jones B, Roe G, Read D, Darrall-Jones J, Weakley J et al. The organised chaos of English adolescent rugby union: Influence of weekly match frequency on the variability of match and training loads. European journal of sport science. 2018;18(3):341-8.

89. Costello N, Deighton K, Preston T, Matu J, Rowe J, Sawczuk T et al. Collision activity during training increases total energy expenditure measured via doubly labelled water. European journal of applied physiology. 2018;118(6):1169-77.

90. Schoenfeld BJ. The mechanisms of muscle hypertrophy and their application to resistance training. The Journal of Strength \& Conditioning Research. 2010;24(10):2857-72. 
91. Argus CK, Gill ND, Keogh JW. Characterization of the differences in strength and power between different levels of competition in rugby union athletes. The Journal of Strength \& Conditioning Research. 2012;26(10):2698-704.

92. Withers RT, Craig NP, Bourdon PC, Norton KI. Relative body fat and anthropometric prediction of body density of male athletes (Graisse corporelle relative et prediction anthropometrique de la densite corporelle d' athletes masculins). European Journal of Applied Physiology. 1987;56(2):191200.

93. Jones B, Till K, Manley A, McGuigan M. A multidisciplinary approach to the profiling and interpretation of fitness testing data: a case study example. Journal Of Australian Strength And Conditioning. 2017;25(1):31-6.

94. Till K, Scantlebury S, Jones B. Anthropometric and Physical Qualities of Elite Male Youth Rugby League Players. Sports medicine (Auckland, NZ). 2017;47(11):2171-86. doi:10.1007/s40279-0170745-8.

95. Harley JA, Hind K, O'Hara JP. Three-compartment body composition changes in elite rugby league players during a super league season, measured by dual-energy X-ray absorptiometry. The Journal of Strength \& Conditioning Research. 2011;25(4):1024-9.

96. Whitehead S, Till K, Weaving D, Dalton-Barron N, Ireton M, Jones B. The Duration-specific Peak Average Running Speeds of European Super League Academy Rugby League Match Play. Journal of strength and conditioning research. 2019.

97. Waldron M, Worsfold PR, Twist C, Lamb K. A three-season comparison of match performances among selected and unselected elite youth rugby league players. Journal of Sports Sciences. 2014;32(12):1110-9.

98. Ackland TR, Lohman TG, Sundgot-Borgen J, Maughan RJ, Meyer NL, Stewart AD et al. Current status of body composition assessment in sport. Sports Medicine. 2012;42(3):227-49.

99. Norton K, Marfell-Jones M, Whittingham N, Kerr D, Carter L, Saddington K et al. Anthropometric assessment protocols. In, Gore, C. (ed.), Physiological tests for elite athletes, Champaign, IL, Human Kinetics, 2000, p.66-85.;2000.

100. Aragon AA, Schoenfeld BJ, Wildman R, Kleiner S, VanDusseldorp T, Taylor L et al. International society of sports nutrition position stand: diets and body composition. Journal of the International Society of Sports Nutrition. 2017;14(1):16.

101. Duthie G, Pyne D, Hooper S. Applied physiology and game analysis of rugby union. Sports medicine. 2003;33(13):973-91.

102. Jackson AS, Pollock ML. Practical assessment of body composition. The Physician and sportsmedicine. 1985;13(5):76-90.

103. Zemski AJ, Broad EM, Slater GJ. Skinfold Prediction Equations Fail to Provide an Accurate Estimate of Body Composition in Elite Rugby Union Athletes of Caucasian and Polynesian Ethnicity. International journal of sport nutrition and exercise metabolism. 2018;28(1):90-9.

doi:10.1123/ijsnem.2017-0251.

104. Nana A, Slater GJ, Stewart AD, Burke LM. Methodology review: using dual-energy X-ray absorptiometry (DXA) for the assessment of body composition in athletes and active people. International journal of sport nutrition and exercise metabolism. 2015;25(2):198-215.

105. Turner CH, Robling AG. Designing exercise regimens to increase bone strength. / Types d ' exercices pour ameliorer la force osseuse. Exercise \& Sport Sciences Reviews. 2003;31(1):45-50. 106. Fredericson M, Chew K, Ngo J, Cleek T, Kiratli J, Cobb K. Regional bone mineral density in male athletes: a comparison of soccer players, runners and controls. British journal of sports medicine. 2007;41(10):664-8. 